\title{
Rancang Bangun Kompor Biomassa Berbahan Dasar Plat Besi dan Beton Dilengkapi Dengan Teknologi Blower
}

\author{
Hadi Santoso \\ Program Studi Teknik Mesin, Fakultas Teknik, Universitas Borneo Tarakan, Jl.Amal Lama No.1, \\ hadisantoso.ubt@gmail.com / hadisantoso@borneo.ac.id
}

\section{Heppi Iromo}

Program Studi Budidaya Perairan, FPIK, Universitas Borneo Tarakan, Jl.Amal Lama No.1, sholat_dhuha@yahoo.co.id

\section{Abstrak}

Telah dibuat kompor biomassa berbahan bakar kayu untuk dimanfaatkan oleh penggiat UKM yang bergerak dibidang pengolahan rumput laut untuk dijadikan berbagai makanan ringan. Kompor dibuat dari plat besi $2 \mathrm{~mm}$ dengan dimensi $30 \mathrm{~cm}$ x $30 \mathrm{~cm}$ x $40 \mathrm{~cm}$ sehingga dapat menampung bahan bakar yang banyak dan tidak mudah habis. Ruang dalam kompor dilapisi dengan beton dari cor semen dengan ketebalan mencapai $5 \mathrm{~cm}$. Kompor ini menggunakan tambahan teknologi blower dari kipas angin untuk membantu proses nyala api, pembakaran dan arah api. Hasilnya kompor biomassa ini mampu digunakan untuk memasak dodol mencapai 5 jam.

Kata Kunci: Kompor Biomassa; Bahan Bakar Kayu, Plat Besi, Blower.

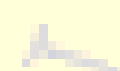

Abstract

Wood-based biomass stoves had been made to be used by UKM entrepreneurs engaged in the seaweed processing into variety of snacks. The stove was made of $2 \mathrm{~mm}$ iron plate with dimensions of $30 \mathrm{~cm} \times 30$ $\mathrm{cm} \times 40 \mathrm{~cm}$ so that it can accommodate a lot of fuel and is not easy to run out. The space in the stove was coated with concrete from a cement which is up to $5 \mathrm{~cm}$ thick. This stove used additional blower technology from the fan in order to help the flaming process, combustion and the direction of fire. The result is that this biomass stove can be used to cook dodol for up to 5 hours.

Keywords: Biomass Stove; Wood Fuel, Iron Plate, Blower.

\section{PENDAHULUAN}

Sumber energi di Indonesia masih dinominasi dengan pemanfaatan minyak bumi dan batu-bara, sehingga penggunaan yang secara terus menerus menimbulkan krisis energi mengakibatkan berkurangnya persediaan sumber energi yang tidak dapat diperbaharui tersebut. Kebutuhan energi Indonesia dari tahun ke tahun mengalami peningkatan seiring dengan meningkatnya pertumbuhan ekonomi dan jumlah penduduk Indonesia [1]. Salah satu penggunaan energi dalam kehidupan sehari-hari adalah memasak. Di negara Indonesia pada umumnya proses memasak masih ketergantungan dengan bahan bakar gas maupun minyak yang notabene jumlahnya semakin sedikit dengan harga yang semakin meningkat drastis tiap tahunnya. Oleh sebab itu, eksplorasi terhadap sumber energi terbarukan lain merupakan solusi yang tepat untuk memenuhi kebutuhan energi yang semakin meningkat. Salah satu energi terbarukan adalah biomassa.

Energi biomassa merupakan energi alternatif yang bersumber dari biomassa yang ketersediaanya cukup banyak di seluruh pelosok negara Indonesia. Hal yang terpenting dari biomassa ini ialah bahan bakarnya dapat dibaharui (renewable). Kayu bakar merupakan salah satu dari energi biomassa dengan nilai kalor $4320 \mathrm{Kkal} / \mathrm{kg}$ [2]. Sebagai negara tropis yang subur, Indonesia memiliki banyak kayu bakar yang mudah diperoleh. Kayu mengandung selulosa dan hemiselulosa dimana kedua unsur ini tersimpan energi kimia yang ketika dibakar akan menghasilkan energi panas yang dapat dimanfaatkan untuk kegiatan rumah tangga dan usaha-usaha lain yang bersifat mekanis seperti mesin perbangkit listrik bertenaga biomassa [3].

Salah satu pihak yang memanfaatkan biomassa dari kayu bakar adalah penggiat UKM produksi makanan olahan dari berbagai bahan, contohnya pengolahan rumput laut menjadi makanan ringan. Proses pembuatan makanan ringan ada yang membutuhkan waktu yang singkat (penggorengan kerupuk rumput laut), bahkan ada yang membutuhkan waktu yang lama seperti dodol rumput laut. Maka dari itu dalam proses memasak mereka lebih memilih menggunakan api dari kayu bakar dibandingkan dengan penggunaan kompor gas maupun minyak. 
Berdasarkan hal tersebut kami tertarik untuk merancang bangun kompor biomassa yang memanfaatkan bahan bakar biomassa yang secara efektif dapat melakukan proses transfer energi panas dengan memanfaatkan bahan dari plat besi dan beton serta dilengkapi teknologi blower untuk penggiat UKM pengolahan bahan makanan dari rumput laut.

\section{METODE}

Perancangan kompor dilakukan dengan mendiskusikan kebutuhan UKM Pembuatan Dodol dengan mempertimbangkan besarnya kuali serta waktu proses pembuatan dodol itu sendiri, sehingga diperoleh gambaran rancangan sebagai berikut;

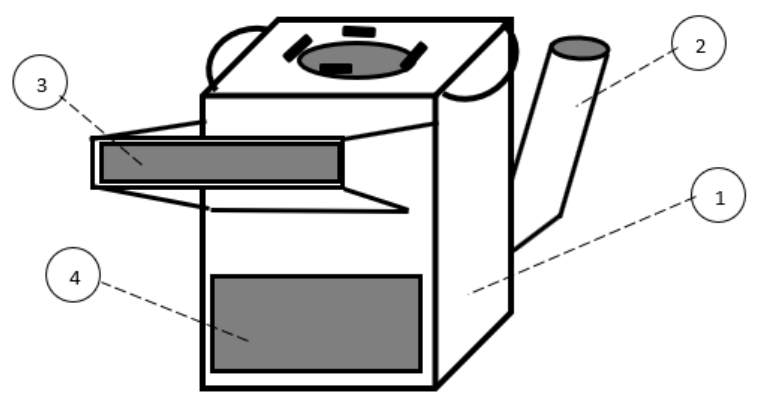

Gambar 1. Rancangan Kompor biomassa

Desain diatas tersusun atas;

(1) Badan kompor,

(2) Pipa saluran udara hembusan blower,

(3) Pintu untuk memasukan bahan bakar biomassa kayu,

(4) Pintu untuk mengeluarkan abu sisa pembakaran.

Dinding utama kompor terbuat dari plat besi dengan tebal $2 \mathrm{~mm}$ yang dirangkai dengan kerangka besi berbentuk balok dengan ukuran panjang $30 \mathrm{~cm}$, lebar 30 $\mathrm{cm}$, dan tingginya $40 \mathrm{~cm}$. Volume yang dibuat cukup luas ini bertujuan agar memberi jumlah bahan bakar yang cukup banyak untuk digunakan dalam proses memasak dodol dalam waktu yang relatif panjang mencapai lebih dari 5 jam. Kerangka disambungkan melalui proses las logam.

Selanjutnya kerangka ditutup dengan plat besi sebagai sisi-sisi balok sedangkan bagian sisi atas dilubangi untuk tempat keluar api menuju bagain bawah kuali. Bagian tersebut disambungkan dengan standar atas kompor penopang wajan maupun panci. Disisi lainya, dibuat pintu untuk tujuan mamasukan bahan bakar tambahan (ditunjukan oleh gambar 1 pada poin 3 dan 4) dengan ukuran tinggi $7 \mathrm{~cm}$ dan panjang $25 \mathrm{~cm}$, dan dibagian bawahnya dibuat lagi pintu dengan tujuan untuk tempat mengeluarkan abu sisa pembakaran dengan ukuran pintu adalah tinggi $15 \mathrm{~cm}$ dan panjangnya $25 \mathrm{~cm}$. Dengan keberadaan kedua pintu ini diharapkan mampu membuat kompor lebih praktis dalam proses menjalankan fungsinya sebagai alat pembakaran biomassa dari kayu bakar. Kedua pintu ini dibuat mampu terbuka dengan bantuan engsel disalah satu sisinya. Dalam pembuatan pintu sebaiknya betul-betul memperhatikan selisih antara pintu dan dinding agar tidak menghasilkan celah yang cukup besar. Bila terjadi celah maka akan mempengaruhi aliran fluida api menuju celah tersebut dan api akan menembus keluar dan akan mengurangi tingkat efektifitasnya sebagai kompor.

Pada gambar 1 terdapat nomor 2 yang merupakan pipa disisi belakang kompor yang tembus mancapai lantai dasar dalam kompor. Tujuan pemasangan pipa ini adalah untuk menambahkan teknologi blower yang mampu menghembuskan udara dari luar menuju ke dalam badan kompor tempat terjadi pembakaran nantinya. Dalam proses terjadinya api, hal yang sangat mempengaruhi timbulnya api adalah oksigen. Semakin banyak keberadaan oksigen, maka semakin mempermudah terjadinya pembakaran api. Dengan adanya hembusan oksigen dari luar yang dihasilkan oleh teknologi blower akan membuat api yang menyala sempurna dan mengurangi terciptanya asap sehingga semua dapat berubah menjadi energi kalor (panas).

Blower yang digunakan adalah kipas angin arus searah (DC) dengan membutuhkan tegangan 3 sampai dengan 12 volt, dengan diamater kipas angin adalah 12 cm disesuaikan dengan ukuran pipa yang tersambung ke badan kompor. Sebagai kontrol kelajuan kipas aingin yang berfungsi pula menaikan deras api yang terjadi dilakukan menggunakan potensiometer yang dapat mengatur kebutuhan tegangan yang masuk ke kipsa angin. Semakin besar tegangan yang diberikan maka akan semakin mempercepat putaran kipas dan menghasilkan hembusan yang lebih besar untuk menimbulkan nyala api yang besar. Sebaliknya bila potensiometer diarahkan pada tegangan yang semakin kecil maka hembusan udara pada kipas angin akan semakin pelan hingga mempengaruhi nyala api yang semakin kecil pula.

Pada lapisan dinding dalam ditambahkan lapisan beton yang terbuat dari semen cor (campuran semen, pasir dan batu kerikil) Yang fungsinya menjadi 2, yakni memperkokoh kompor sehingga kompor akan sulit untuk jatuh, dan fungsi lapisan beton lainnya adalah mengurangi dampak kalor api yang lansung diterima oleh lapisan dinding besi. Bila terjadi paparan kalor secara lansung dan terus menerus terhadap dinding kompor maka akan menyebabkan sisi dalam besi mengalami pemuaian yang akan mempengaruhi kekokohan kompor. Selain mengantisipasi pemuaian yang cukup besar, tujuannya pula untuk menghasilkan energi kalor yang fokus digunakan untuk proses pembakaran biomassa kayu bakar dan tidak banyak terbuang di dinding kompor itu sendiri 
Setelah dilakukan perancangan kompor, selanjutnya dilakukan pembangunan kompor sesuai rancangan yang telah direncanakan.
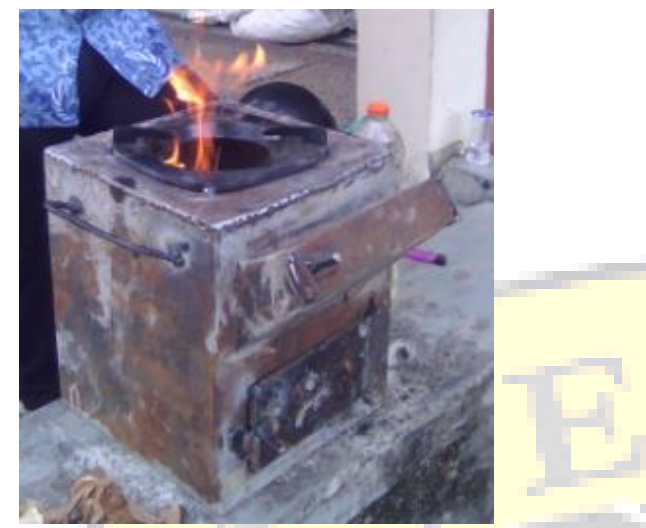

Gambar 2. Bentuk kompor dan Uji coba nyala api

Selanjutnya dilakukan proses ujicoba untuk menghitung penggunaan bahan bakar, yang dihitung dengan cara menggurangkan berat bahan bakar yang dimasukkan ke dalam kompor biomassa dikurangi dengan berat bahan bakar sisa [3];

$$
\mathrm{PBB}=\mathrm{BBM}-\mathrm{BBS}
$$

\section{Dimana;}

$P B B$ adalah Penggunaan Bahan Bakar $(\mathrm{kg})$

$B B M$ adalah Bahan bakar masuk, $(\mathrm{kg})$

$B B S$ adalah Bahan Bakar Sisa (BBS).

Dalam proses pembakaran dapat lansung diisi penuh oelh bahan bakar maupun sebagian saja. Sejumlah $5 \mathrm{~kg}$ ranting kayu kering sudah mampu mengisi penuh kompor ini, yang setelah diujicoba untuk mendidihkan 5 liter air ternyata membutuhkan waktu kurang dari 3 menit untuk mencapai titik didih.

Besar kecilnya aliran fluida dapat dikontol melalui potensiometer yang mempengaruhi cepat tidaknya putaran kipas angin sebagai blower seperti gambar 3 .

\section{HASIL DAN PEMBAHASAN}

Setelah mengalami ujicoba dalam proses memasak, dilakukan pula analisa penggunaan bahan bakar. Hasilnya setelah diujicoba maka diperoleh data $B B M$ (Bahan Bakar Masuk) $=5,0 \mathrm{~kg}, B B S$ (Bahan bakar sisa) $=3,6 \mathrm{~kg}$, Sehingga; $P B B$ (Penggunaan Bahan Bakar); 5,0 kg - 3,6 $\mathrm{kg}=1,4 \mathrm{~kg}$.

Ujicoba diatas memperlihatkan bahwa penggunaan bahan bakar dalam waktu yang singkat ternyata cukup banyak menghabiskan bahan bakar. Dari total $5 \mathrm{~kg}$ ranting terpakai sebanyak $28 \%$ hanya dalam waktu 3 menit saja sehingga menyisakan $3,6 \mathrm{~kg}$ ranting yang telah berubah menjadi arang. Hal ini dsebabkan 2 hal, yakni

1. Ranting yang digunakan tergolong berukuran kecil dengan rata-rata berdiameter $0,5 \mathrm{~cm}$ yang sifatnya mudah habis terbakar.

2. Proses pemadaman yang cukup lama pasca air telah mendidih menyebabkan banyak ranting yang telah terbakar dan menjadi arang dan sisinya menjadi abu.

Namun dalam tugasnya sebagai alat yang menghantarkan energi kalor dapat dikatakan bahwa kompor ini telah berhasil untuk menyalakan api yang konsisten dengan kalor yang cukup baik untuk menunjang pembakaran biomassa kayu bakar dalam proses untuk memasak, baik memasak air yang notabene memerlukan waktu yang singkat, bahkan memasak yang membutuhkan waktu yang lama seperti memasak dodol. Dalam proses memasak yang membutuhkan waktu lama, kompor ini akan dapat dengan baik mengkonversi seluruh bahan bakar biomassa kayu bakar untuk menjadi api dan kalor yang dihasilkannya akan ditransfer menuju kuali dengan cara radiasi di pusat lubang atas kompor, serta konduksi melalui sisi-sisi kompor yang terdiri dari plat besi dan beton, sehingga kalor yang dihasilkan cukup lama untuk menunjang proses memasak yang membutuhkan waktu yang relatif panjang.

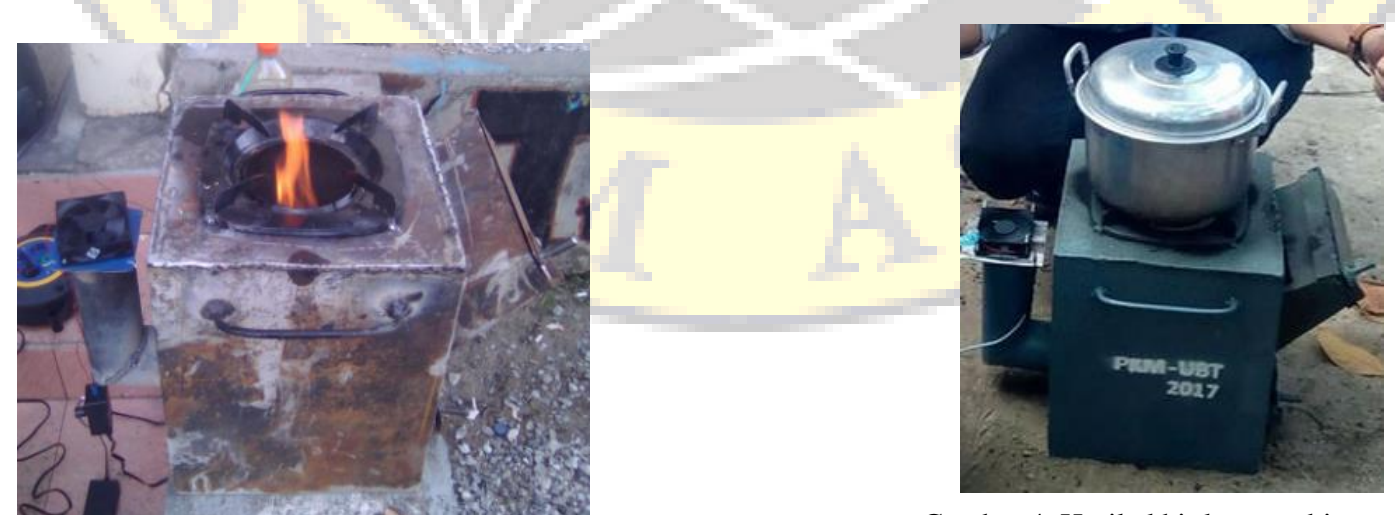

Gambar 3. Kompor tampak samping dengan penampakan teknologi blower

Gambar 4. Hasil akhir kompor biomassa yang siap digunakan 


\section{PENUTUP}

Berdasarkan hal yang telah dijabarkan diatas dapat disimpulkan bahwa;

1. Rancang bangun kompor berbahan utama berdinding plat besi dilapisi oleh lapisan beton telah mampu dengan baik mengkonversi energi biomassa dari kayu bakar menjadi energi kalor yang berupa fluida api yang desbarkan secara konduksi dan radiasi menuju kuali dalam proses memasak.

2. Kompor berteknologi blower dengan sistem kontrol kecepatan sangat mempengaruhi dalam pembuatan api dan kualitas nyala api yang dihasilkan kompor biomassa kayu bakar.

3. Volume kompor akan mempengaruhi jumlah bahan bakar yang tersedia dalam proses pembakaraan biomassa dalam proses memasak, khususnya memasak dodol rumput laut yang membutuhkan waktu yang relatif lama.

Dalam prosesnya didapati beberapa kendala sehingga diharapkan menjadi pertimbangan untuk memperbaiki kondisi kompor biomassa ini. Saran yang dapat kami berikan untuk meningkatkan kompor ini menjadi lebih baik adalah sebagai berikut;

1. Diperlukan rencana dan perhitungan yang lebih detail dalam pemasangan teknologi blower agar pengaruh hembusan angin dapat secara efetif dalam proses menyalakan api, dan mengurangi tingkat kerusakan terhadap blower itu sendiri akibat energi kalor yang diterimanya.

2. Diperlukan analisa dan ujicoba penggunaan bahan lain penyusun kompor untuk mengurangi terbuangnya energi kalor pada dinding kompor.

3. Dibutuhkan teknologi yang murah dan praktis dalam memadamkan nyala api secara cepat sehingga mengurangi jumlah bahan bakar yang habis dalam proses memadamkan api.

\section{DAFTAR PUSTAKA}

[1] Ana Fitriyatus Sa'adah, dkk. 2017. Peramalan Penyediaan dan Konsumsi Bahan Bakar Minyak Indonesia dengan Model Sistem Dinamik. Biro Perencanaan Kementerian ESDM. Jurnal Ekonomi dan Pembangunan Indonesia Vol. 17 No. 2 Januari 2017: 118-137

[2] Yudanto. dan Kusumaningrum, 2009. Pembuatan Briket Bioarang Dari Arang Serbuk Gergaji Kayu Jurusan Teknik Kimia Fakultas. Teknik Universitas Diponegoro.Semarang.

[3] Wakur, Roni. dkk. 2015. Kompor Biomassa Menggunakan Bahan Bakar Kayu Cengkeh (Syzygium Aromaticum (L.) Merr) Sebagai Sumber Energi. ejournal.unsrat.ac.id. Vol 6, No 13 (2015). 